\title{
Electrofragmentation modeling of conductive coatings on polymer substrates
}

\author{
Yves Leterrier, a) Albert Pinyol, Luc Rougier, Judith H. Waller, and Jan-Anders E. Månson \\ Laboratoire de Technologie des Composites et Polymères (LTC), Ecole Polytechnique Fédérale de \\ Lausanne (EPFL), CH 1015 Lausanne, Switzerland
}

(Received 8 June 2009; accepted 26 October 2009; published online 3 December 2009)

\begin{abstract}
Damage occurring under tensile loading and the resulting increase in electrical resistance of tin-doped indium oxide and amorphous graphite coatings on various polymer substrates are investigated, using an electrofragmentation method in situ in an optical microscope. The electrical resistance is modeled as a function of damage state assuming that the resistance of coating cracks is proportional to their opening, and that there exists a conducting path of constant thickness at the coating/substrate interface across the crack. The model reproduces the experimental data with good accuracy apart from the damage initiation and saturation stages where it underestimates the measured coating resistance. This is due to the presence of stable cracks of finite length in the initiation stage and delamination in the saturation stage. Impedance spectroscopy measurements confirm the purely resistive nature of the conducting path, whose resistivity is found to be three to four orders of magnitude higher than that of the uncracked coating. (C) 2009 American Institute of Physics. [doi:10.1063/1.3266001]
\end{abstract}

\section{INTRODUCTION}

Flexible electronics based on polymer substrates attract a great deal of attention for applications as diverse as displays, ${ }^{1,2}$ stretchable $^{3}$ and wearable computing, ${ }^{4}$ and photovoltaic cells. ${ }^{5,6}$ In all cases the devices are multilayer structures with thin film stacks including inorganic diffusionbarrier and electrode layers. The advantages of using polymer substrates are their flexibility, robustness, and potential for lightweight applications, in addition to their compatibility with cost-effective roll-to-roll process methods. These advantages may, however, be compromised by problems in mechanical integrity such as layer cracking and delamination, due to the considerable hygrothermomechanical contrast between the inorganic brittle device layers and the compliant polymer substrates. Stretchable thin film electrodes have been reported, which provide effective solutions to this problem (e.g., Refs. 7-9)

The mechanical analysis of thin brittle films on compliant polymer substrates is usually carried out under quasistatic tensile, ${ }^{10-12}$ bending, and compressive loadings. ${ }^{13}$ It is greatly complicated by the nanometric nature of the investigated layers. Analysis of damage processes in situ under a microscope is an accurate method for determining the critical factors that control the integrity of such thin films. The focus of the present work is on brittle conductive coatings, including tin-doped indium oxide films developed as transparent electrodes for organic light-emitting displays and solar cells. In this case, the simultaneous measurement of electrical resistance and crack detection enabled the onset of tensile failure to be ascertained with excellent resolution. ${ }^{14,15}$ The same combination of methods also enabled monitoring overall damage evolution under fatigue. ${ }^{16,17}$ The measured sudden

\footnotetext{
${ }^{a)}$ Author to whom correspondence should be addressed. Electronic mail: yves.leterrier@epfl.ch. FAX: +41216935880.
}

increase in electrical resistance during tensile loading was correlated with the onset of unstable crack propagation (see Chap. 6 of Ref. 1), but progressive damage at a higher strain, and the resulting changes in electrical resistance were not specifically studied. The aim of this work was thus to identify the main damage mechanisms (crack initiation, propagation, and eventual coating delamination) from an analysis of resistance measurements. This would enable systematic studies to be carried out of mechanical failure of thin films on polymers both as a function of strain rate and under fatigue loading, similar to health monitoring methods (e.g., Refs. 18-20). It would moreover constitute a powerful alternative to the rather impracticable optical detection of cracks in the case of experiments that may last only a few seconds (high strain rate), or several days, or weeks (low strain rate and fatigue).

\section{MATERIALS AND EXPERIMENTAL METHODS}

Three different types of conductive coatings on polymer substrates were considered, with a broad range of sheet resistivity. Tin-doped indium oxide (ITO) coatings with thicknesses equal to 50,100, and $130 \mathrm{~nm}$ were sputtered from 10 wt $\% \mathrm{SnO}_{2}+90$ wt $\% \mathrm{In}_{2} \mathrm{O}_{3}$ targets using a dc magnetron source at ambient temperature on a $100 \mu \mathrm{m}$ thick, high temperature aromatic polyester film (Arylite ${ }^{\mathrm{TM}}$, Ferrania Imaging Technologies) coated with a $4 \mu \mathrm{m}$ thick acrylate-silica hybrid coating, used as a scratch resistant and solvent barrier. The sheet resistivity of the ITO coatings was equal to $122 \Omega$ /sq $(50 \mathrm{~nm}), 63 \Omega / \mathrm{sq}(100 \mathrm{~nm})$, and $55 \Omega / \mathrm{sq}(130$ $\mathrm{nm}$ ). A layered, $136 \mathrm{~nm}$ thick ITO-Ag (ITO $30 \mathrm{~nm} / \mathrm{Ag} 8$ nm/ITO $60 \mathrm{~nm} / \mathrm{Ag} 8 \mathrm{~nm} / \mathrm{ITO} 30 \mathrm{~nm}$, ITOA) coating was deposited on a $50 \mu \mathrm{m}$ thick polyethylene terephthalate film (PET, Dupont Teijin DT401). Its sheet resistivity was $4 \Omega$ /sq. A $26 \mathrm{~nm}$ thick amorphous graphite (a-G) coating was deposited on a $9 \mu \mathrm{m}$ thick polyimide film using a 
TABLE I. Fragmentation data and electrical properties of coatings on polymer substrates.

\begin{tabular}{|c|c|c|c|c|c|}
\hline $\begin{array}{l}\text { Coating/substrate } \\
\text { structure }\end{array}$ & $\begin{array}{l}\text { Crack onset } \\
\text { strain, } \varepsilon_{1}\end{array}$ & $\begin{array}{l}\text { Crack density at saturation, } N \\
\left(\left(\mathrm{~mm}^{-1}\right)\right.\end{array}$ & $\begin{array}{l}\text { Cracking } \\
\text { rate, } A\end{array}$ & $\begin{array}{l}\text { Coating resistivity, } \rho \\
(\mu \Omega \mathrm{cm})\end{array}$ & $\begin{array}{c}\text { Crack resistivity, }{ }^{\mathrm{a}} \rho_{c} \\
(\mu \Omega \mathrm{cm})\end{array}$ \\
\hline $\mathrm{a}-\mathrm{G} 26 \mathrm{~nm} / \mathrm{PI}$ & 0.0110 & $1000^{\mathrm{b}}$ & 16 & $50 \times 10^{3}$ & $2.33 \times 10^{8}$ \\
\hline ITO $50 \mathrm{~nm} / \mathrm{ARY}$ & 0.0215 & 180 & 77 & 610 & $4.13 \times 10^{6}$ \\
\hline ITO $100 \mathrm{~nm} / \mathrm{ARY}$ & 0.0142 & 145 & 140 & 634 & $9.11 \times 10^{6}$ \\
\hline ITO $130 \mathrm{~nm} / \mathrm{ARY}$ & 0.0085 & 108 & 60 & 715 & $1.08 \times 10^{7}$ \\
\hline ITOA 136 nm/PET & 0.0110 & 126 & 65 & 59 & $2.15 \times 10^{5}$ \\
\hline
\end{tabular}

${ }^{\mathrm{a} C a l c u l a t e d}$ using $W=5 \mathrm{~mm}, \lambda_{0}=100 \mu \mathrm{m}$, and $t=1 \mathrm{~nm}$.

${ }^{\mathrm{b}}$ Fitted value.

Cressington 208 carbon coater with a mtm10 thickness monitor. Its sheet resistivity was $42 \mathrm{k} \Omega / \mathrm{sq}$. The resistivity of the different coatings materials is reported in Table I.

Fragmentation tests ${ }^{10,21}$ were carried out at room temperature in situ under an optical microscope (Olympus BX60). A miniature tensile testing apparatus (Minimat, Rheometric Systems) equipped with special clamps to enable simultaneous measurement of electrical resistance and density of tensile cracks was used, following a "stress and stop" approach detailed elsewhere. ${ }^{14}$ Rectangular samples of 50 $\mathrm{mm}$ length and $5 \mathrm{~mm}$ width were cut from the coated films. Video-extensometry was used for strain measurement, with an accuracy of $10^{-4}$, and the electrical resistance was measured using multimeters (Hewlett-Packard 3468A and Agilent 34401A).

\section{RESULTS AND DISCUSSION}

\section{A. Phenomenology of coating fragmentation}

Figure 1 shows the damage state of the ITOA coating on PET at different tensile strain levels. The early fragmentation stages were characterized by the initiation of cracks of finite length [Fig. 1(a)], which propagated until they reached a critical size and became unstable. ${ }^{22}$ At higher strain levels, all cracks reached the unstable regime and a high crack density was evident [Fig. 1(b)]. In the saturation stage [Fig. $1(\mathrm{c})]$, transverse buckling damage was observed and the cracking rate slowed down considerably, with progressive interfacial delamination.

The increase in crack density versus strain is reproduced in Fig. 2 for all investigated films. The crack density, $k$, was obtained from the average number of full cracks (i.e., spanning the whole micrograph) counted on a minimum of five micrographs, and multiplying the result by $(1+\varepsilon)$ to account for crack opening to a first approximation, $\varepsilon$ being the strain.

It is evident that for coatings of given composition (ITO coatings in the present study) hence given fracture toughness, the crack onset strain, and the crack density at saturation increase with decreasing coating thickness. ${ }^{21}$ This trend is not followed by the ITOA coating, which reflects the change in fracture toughness of the oxide resulting from the incorporation of silver.

The experimental data $k(\varepsilon)$ were fitted using the following equation:

$$
k(\varepsilon)=N\left(1-\exp \left\{-A\left(\varepsilon-\varepsilon_{1}\right)\right\}\right),
$$

where $N$ represents the crack density at saturation of the fragmentation process, $A$ is an adjustable factor, which reflects cracking rate related to, e.g., the coating Weibull modulus, ${ }^{21}$ and $\varepsilon_{1}$ is the measured critical failure strain (also termed crack onset strain, corresponding to the onset of un-
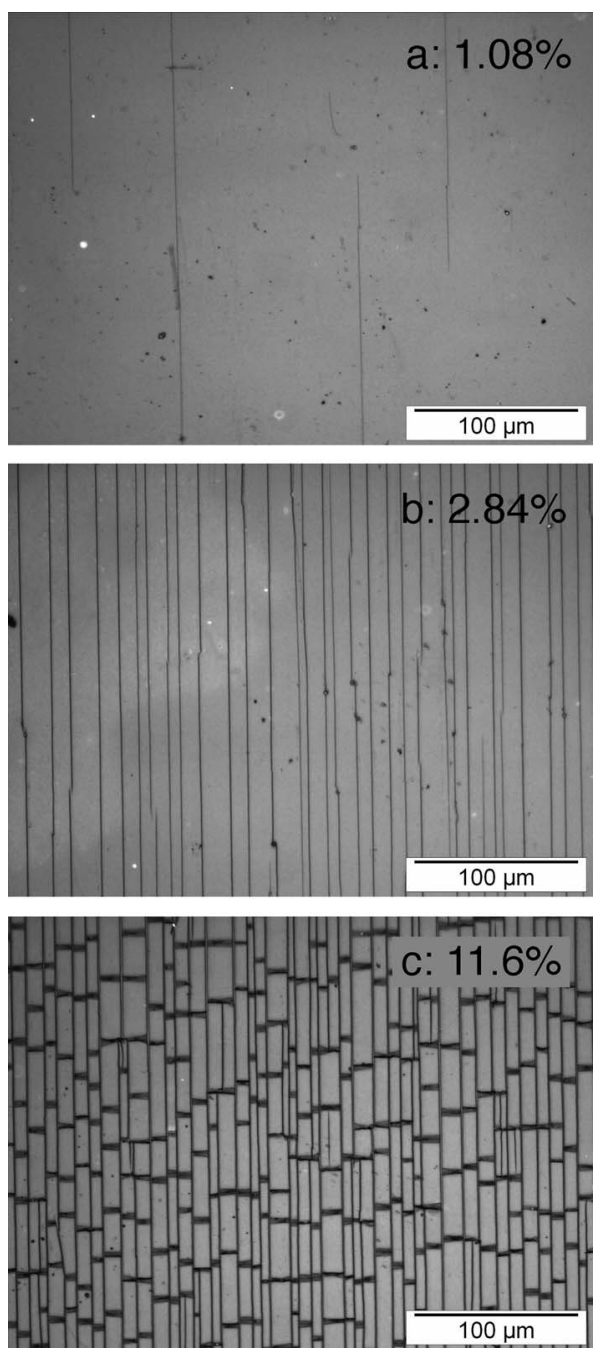

FIG. 1. Damage state of a $136 \mathrm{~nm}$ thick ITOA coating on PET at three strain levels. Tensile loading was applied parallel to the scale bar in the optical micrographs. At $1.08 \%$ strain (a) initial cracks of finite length are detected. At $2.84 \%$ strain (b) numerous cracks have propagated and form a dense array with a density of approximately $90 \mathrm{cracks} / \mathrm{mm}$. At $11.6 \%$ strain (c) the fragmentation process has reached the saturation state and transverse buckling damage is visible (dark features perpendicular to the cracks). 


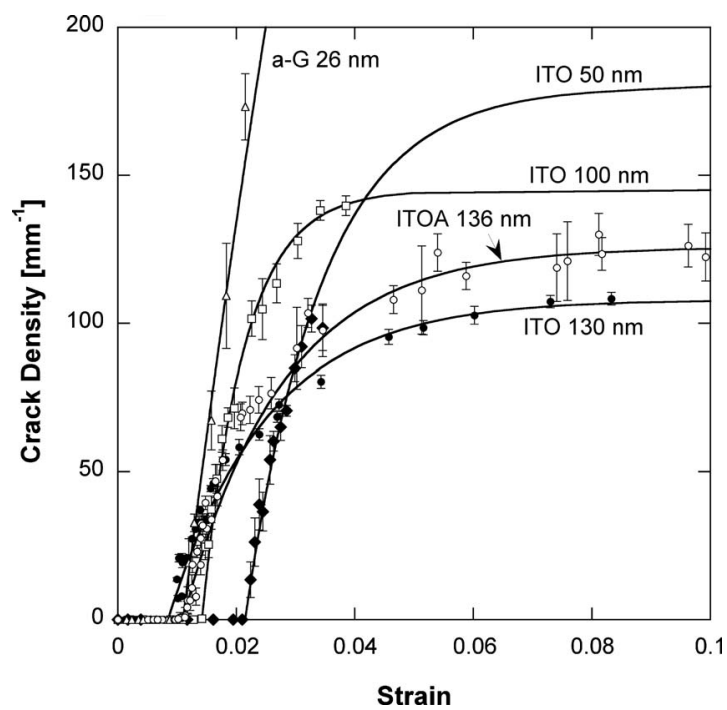

FIG. 2. Crack density vs strain for conducting coatings on polymer substrates. The solid lines represent Eq. (1).

stable propagation of the first crack). Crack density at saturation was not measured in the case of the ITO and the a-G coatings but was left as an adjustable parameter. The fitted function reproduced the measured data with good accuracy and will be used in Sec. III B to model the increase in electrical resistance. ${ }^{22}$ The values of the parameters are reported in Table I. A similar expression to Eq. (1), proposed by Ignat, $^{23}$ also included an exponent representing the Weibull modulus. Their model was also tested in the present work, but it added unnecessary complications with little change in the final results.

Figure 3 depicts the normalized increase in electrical resistance $\Delta R / R_{0}$ of the investigated materials, where $\Delta R$ $=R-R_{0}$ represents the change in electrical resistance $R$, and $R_{0}$ is the resistance of the unstrained specimen. The increase

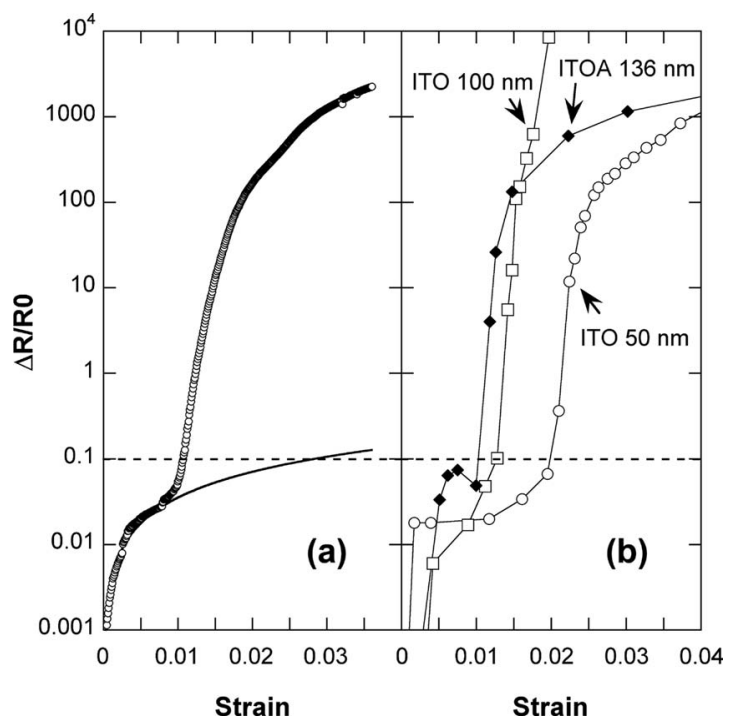

FIG. 3. Normalized change of electrical resistance vs strain for conducting coatings on polymer substrates [(a) a-G coating, continuous measurement; (b) ITO coatings as indicated, discontinuous measurements]. The increase in electrical resistance due to the strain gauge effect is also shown as a solid line for the a-G coating. The criterion for coating failure set at a $10 \%$ resistance increase is shown as a horizontal dotted line. in the electrical resistance of the a-G coating upon straining at a constant strain rate is shown in Fig. 3(a). A marked transition was evident at $1 \%$ strain, which corresponded to the onset of tensile failure of the graphite coating (Fig. 2). ${ }^{15}$ Below this threshold, the resistance increase resulted from the strain gauge effect $\Delta R / R_{0}=S \times \varepsilon$, where $S$ is a strain sensitivity constant. ${ }^{24}$ Above this threshold, the resistance increased by many orders of magnitude, but was still measurable, in spite of the very high density of tensile cracks. This implied that cracks have a finite resistance, a fact that motivated the model introduced in Sec. III B. The same behavior was observed for the other types of coatings, as shown in Fig. 3(b). In these cases the resistance was measured at selected strain levels, not continuously, as was required for an accurate analysis of the damage state of the coating in situ under the microscope. The criterion for coating cracking as a $10 \%$ increase in electrical resistance, ${ }^{15}$ shown as a dotted line in the figure, correlated very well with the fragmentation data shown in Fig. 2.

\section{B. Modeling the influence of tensile damage on electrical resistance}

The increase in electrical resistance of the coating under strain was modeled by summing the resistance of individual cracks in series, as in previous investigations. ${ }^{25}$ Thus

$$
R(\varepsilon)=R_{0}+\sum_{i=1}^{k} R_{i}(\varepsilon),
$$

where $R_{0}$ is the resistance of the undamaged coating (the very small increase in coating resistance upon straining shown in Fig. 3, i.e., the strain gauge effect, was disregarded), $k$ is the crack density at strain $\varepsilon$, and $R_{i}$ is the straindependent resistance of crack $i$ :

$$
R_{i}(\varepsilon)=\rho_{c} \frac{\lambda_{i}(\varepsilon)}{t W} .
$$

The above equation implies the existence of a conductive path in the crack, in the form of a residual layer at the substrate surface, with resistivity $\rho_{c}$ and constant thickness $t$. The existence of such a conducting path will be checked later in this section. Moreover, Eq. (3) does not follow the constant volume approach for the conducting path as has been reported elsewhere. ${ }^{25}$ The latter approach would be appropriate for yielding conductors, which is not, however, the case for the investigated coatings. However, it will be examined at a later stage in the paper. The factor $W$ represents the crack length, which is equal to the sample width for cracks beyond the unstable propagation limit. The factor $\lambda_{i}(\varepsilon)$ is the crack opening function proportional to strain $\varepsilon .{ }^{26}$ This results in

$$
\lambda_{i}(\varepsilon)=\lambda_{0}\left(\varepsilon-\varepsilon_{i}\right)
$$

where $\lambda_{0}$ is a length scale and $\varepsilon_{i}$ is the strain at which crack $i$ forms. The latter strain was obtained from Eq. (1), by replacing strain $\varepsilon$ by strain $\varepsilon_{i}$ and inverting the equation.

Using Eqs. (3) and (4), Eq. (2) then takes the form 


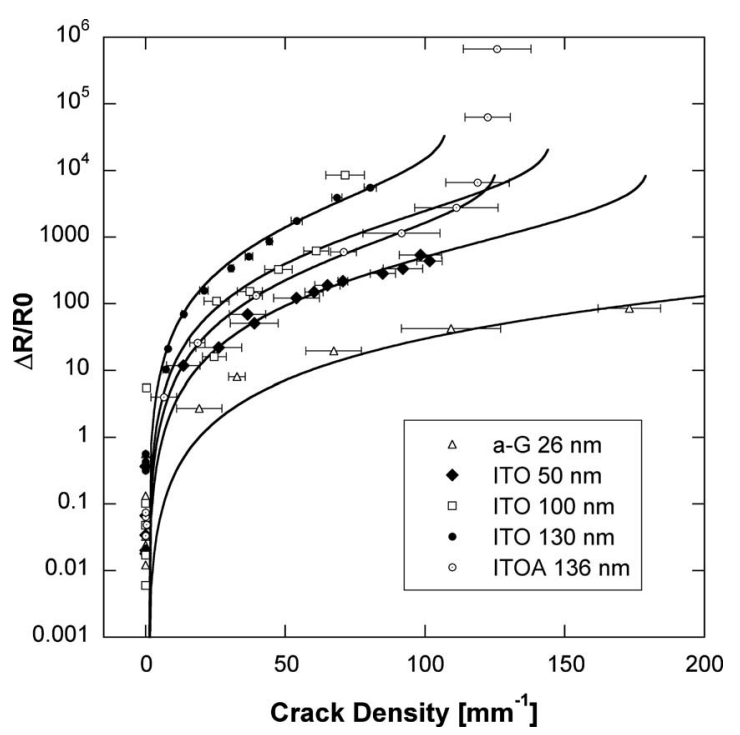

FIG. 4. Normalized increase in electrical resistance vs crack density of conducting coatings on polymer substrates. The solid lines represent the model based on a conductive path of constant thickness at the coating/ substrate interface [Eq. (6)] with an adjustable crack resistance factor.

$$
\begin{aligned}
R(k) & =R_{0}+\rho_{c} \frac{\lambda_{0}}{t W} \sum_{i=1}^{k}\left(\varepsilon-\varepsilon_{i}\right) \\
& =R_{0}+\rho_{c} \frac{\lambda_{0}}{t W} \frac{1}{A} \sum_{i=1}^{k}\left(-\operatorname{Ln}\left\{1-\frac{k}{N}\right\}+\operatorname{Ln}\left\{1-\frac{i}{N}\right\}\right) .
\end{aligned}
$$

By transforming the sum of logarithms into factorial products, one obtains the final form:

$$
R(k)=R_{0}+\rho_{c} \frac{\lambda_{0}}{t W} \frac{1}{A} \operatorname{Ln}\left\{\frac{(N-1) !}{(N-k)^{k}(N-k-1) !}\right\} .
$$

This nonlinear formulation reflects the combined influence of the progressive increase in the number of cracks and the correlated opening of these cracks. The normalized increase $\left[R(k)-R_{0}\right] / R_{0}$ is depicted in Fig. 4 and was fitted to experimental data using an adjustable crack resistance factor $\rho_{c}\left(\lambda_{0} / t W\right)$ with $\rho_{c}$ values reported in Table I. It is clear that the model reproduced the measured data for all investigated films in most of the crack density range, in spite of a rather simple hypothesis of crack resistance being proportional to crack opening [Eq. (4)]. In the early fragmentation stages (low crack density), the model underestimated the actual resistance increase. This was due to the presence of short cracks [Fig. 1(a)] that contributed to a moderate increase in resistance and which were not included in the present analysis. Specific models were developed to analyze the conductivity of solids with a population of microcracks, including an exponential dependence with crack length and density, ${ }^{27,28}$ but these were not applicable when the crack length was infinite (or equal to the sample size as in the present case). In the case of the ITOA/PET film, which was analyzed up to the saturation stage, the model considerably underestimated the electrical resistance at high crack density, probably as a result of delamination when approaching the saturation stage [Fig. 1(c)].

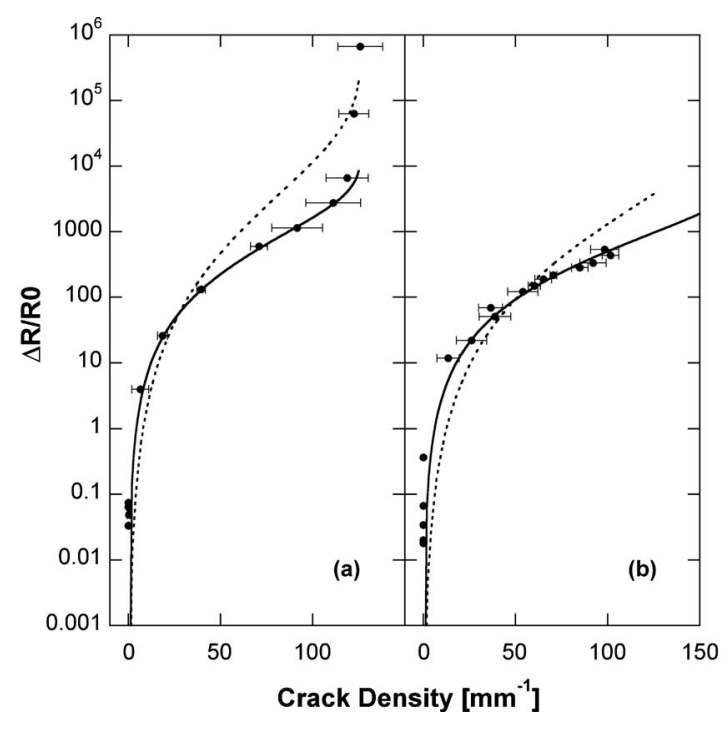

FIG. 5. Normalized increase in electrical resistance vs crack density of conducting coatings on polymer substrates [(a) $136 \mathrm{~nm}$ thick ITOA coating; (b) $50 \mathrm{~nm}$ thick ITO coating]. The solid and dashed lines represent the constant thickness [Eq. (6)] and constant volume [Eq. (7)] models, respectively.

In the case where the volume-and not the thickness-of the conducting path was constant, and using the present crack density model [Eq. (1)], one obtains

$$
R(k)=R_{0}+\rho_{c} \frac{\lambda_{0}^{2}}{v} \sum_{i=1}^{k}\left[\operatorname{Ln}\left\{\left(\frac{N-k}{N-i}\right)^{-1 / A}\right\}\right]^{2},
$$

where $v$ is the volume of the conducting path, and the factor $\rho_{c}\left(\lambda_{0}^{2} / v\right)$ represents the resistance of the crack. The constant thickness [Eq. (6)] and constant volume [Eq. (7)] models were fitted to the experimental data for the $50 \mathrm{~nm}$ thick ITO and the $136 \mathrm{~nm}$ thick ITOA coatings shown in Fig. 5. Both models were able to describe the low crack density regime, but the constant volume model failed to match the rate of resistance increase. If the hypothesis of a conducting path at the substrate surface is correct, this result suggests that it is not a layer of yielding material but, in fact, a residual layer of the coating material still adhering to the substrate between coating fragments.

In the constant thickness approach, the resistivity $\rho_{c}$ and thickness $t$ of the conducting path were related to the fitted values of the crack resistance factor $\rho_{c}\left(\lambda_{0} / t W\right)$. Assuming first that $\rho_{c}$ was equal to the measured coating resistivity $\rho$ (sheet resistance $\times$ coating thickness) reported in Table I, and assuming that the crack opening factor $\lambda_{0}=100 \mu \mathrm{m}$ (so that the actual crack opening was of the order of $1 \mu \mathrm{m}$ ), then this led to a conducting path thickness $t$ of the order of $10^{-13} \mathrm{~m}$. This unrealistic value (increasing $\lambda_{0}$ by a factor of $100 \mathrm{did}$ not help) implied that the resistivity of the postulated conducting path should be much higher than that of the coating. Setting $t=1 \mathrm{~nm}$ (and $\lambda_{0}=100 \mu \mathrm{m}$ ), one obtains $\rho_{c}$ values three to four orders of magnitude higher than that of the coating, as shown in Table I.

The nature of the conducting mechanism and the existence of an interfacial conducting layer were checked in the case of the ITOA/PET films by using impedance spectros- 
copy measurements in the $100 \mathrm{~Hz}-100 \mathrm{kHz}$ frequency range (Network Analyzer Anritsu MS4630B). An unstrained film and a film first uniaxially strained to $10 \%$ and later unloaded were analyzed, both in the form of $5 \times 20 \mathrm{~mm}^{2}$ rectangular specimens. In both cases, a shunt resistance of $47 \Omega$ was connected to the specimen, and electrical contacts with the ITOA coating were made using a Ag colloid conducting paste. For both unstrained and strained films, the impedance was found to be constant in the investigated frequency range, with attenuation equal to approximately $60 \mathrm{~dB}$ between the intact and the cracked coatings. This result indicated that the conduction mechanism was purely resistive and that, in the case of the cracked coating, capacitance effects could be disregarded [i.e., Eq. (2) is valid]. The structure and formation of the conducting path remain to be elucidated. Constant thickness implies material transport from the coating to the polymer surface. This process would be rate dependent, which could be analyzed using electrofragmentation tests carried out at different strain rates. Further insight into the interfacial conducting path could be gained using methods such as conducting and Kelvin probe force microscopies. ${ }^{29}$ At the present state of knowledge of the conducting mechanism, the electrofragmentation approach should be a useful tool for automatic monitoring of the damage state and longterm fatigue behavior of conducting coatings on strained substrates using real-time and accurate electrical resistance measurements.

\section{CONCLUSIONS}

A model was developed to correlate the tensile damage of conducting coatings on polymer substrates to the increase in electrical resistance upon straining. The model assumed the existence of an interfacial path of constant thickness between coating fragments. The purely resistive nature of the conducting path was verified using impedance spectroscopy measurements. An alternative model based on a constant volume path was found to overestimate the resistance increase. The constant thickness path model reproduced experimental data in most of the crack density range apart from the damage initiation and saturation stages where it underestimated the measured coating resistance. This was due to the presence of stable cracks of finite length in the initiation stage and delamination in the saturation stage. The resistivity of the conducting path was found to be three to four orders of magnitude higher than that of the uncracked coating.

\section{ACKNOWLEDGMENTS}

The authors are grateful to the EU-funded Flexidis project (Grant No. IST-004354) for funding this work, and to the companies Applied Materials, Unaxis Balzers Ltd., Displays Division, and Philips for film samples. They also acknowledge Pierre Zweiacker (EPFL) for his help with the impedance spectroscopy measurements.

${ }^{1}$ Flexible Flat Panel Displays, edited by G. P. Crawford (Wiley, Chichester, England, 2005).

${ }^{2}$ W. A. MacDonald, J. Mater. Chem. 14, 4 (2004).

${ }^{3}$ S. P. Lacour, J. Jones, S. Wagner, T. Li, and Z. G. Suo, Proc. IEEE 93, 1459 (2005)

${ }^{4}$ S. L. P. Tang, Trans. Inst. Meas. Control (London) 29, 283 (2007).

${ }^{5}$ X. Mathew, G. W. Thompson, V. P. Singh, J. C. McClure, S. Velumani, N. R. Mathews, and P. J. Sebastian, Sol. Energy Mater. Sol. Cells 76, 293 (2003).

${ }^{6}$ J. M. Kroon, N. J. Bakker, H. J. P. Smit, P. Liska, K. R. Thampi, P. Wang, S. M. Zakeeruddin, M. Gratzel, A. Hinsch, S. Hore, U. Wurfel, R. Sastrawan, J. R. Durrant, E. Palomares, H. Pettersson, T. Gruszecki, J. Walter, K. Skupien, and G. E. Tulloch, Prog. Photovoltaics 15, 1 (2007).

${ }^{7}$ E. Artukovic, M. Kaempgen, D. S. Hecht, S. Roth, and G. Grüner, Nano Lett. 5, 757 (2005).

${ }^{8}$ D. P. Wang, F. Y. Biga, A. Zaslavsky, and G. P. Crawford, J. Appl. Phys. 98, 086107 (2005).

${ }^{9}$ S. Befahy, S. Yunus, T. Pardoen, P. Bertrand, and M. Troosters, Appl. Phys. Lett. 91, 141911 (2007).

${ }^{10}$ Y. Leterrier, Prog. Mater. Sci. 48, 1 (2003).

${ }^{11}$ G. Rochat, Y. Leterrier, J.-A. E. Månson, and P. Fayet, Thin Solid Films 437, 204 (2003).

${ }^{12}$ J. Andersons, Y. Leterrier, G. Tornare, P. Dumont, and J.-A. E. Månson, Mech. Mater. 39, 834 (2007).

${ }^{13}$ A. A. Abdallah, D. Kozodaev, P. C. P. Bouten, J. M. J. den Toonder, U. S. Schubert, and G. de With, Thin Solid Films 503, 167 (2006).

${ }^{14}$ Y. Leterrier, L. Médico, F. Demarco, J.-A. E. Månson, M. Escola-Figuera, M. Kharrazi-Olsson, U. Betz, and F. Atamny, Thin Solid Films 460, 156 (2004).

${ }^{15}$ A. Pinyol, B. Meylan, D. Gilliéron, V. Mewani, Y. Leterrier, and J.-A. E. Månson, Thin Solid Films 507, 2007 (2009).

${ }^{16}$ D. R. Cairns and G. P. Crawford, Proc. IEEE 93, 1451 (2005).

${ }^{17}$ T. Koniger and H. Munstedt, Meas. Sci. Technol. 19, 055709 (2008).

${ }^{18}$ J. H. Constable and C. Sahay, IEEE Trans. Compon., Hybrids, Manuf. Technol. 15, 1138 (1992).

${ }^{19}$ S. Hirano, A. Kishimoto, and M. Miyayama, J. Eur. Ceram. Soc. 19, 2087 (1999).

${ }^{20}$ K. J. Loh, T. C. Hou, J. P. Lynch, and N. A. Kotov, Nanotube-Based Sensing Skins for Crack Detection and Impact Monitoring of Structures (Destech, Stanford, CA, 2007), pp. 1685-1692.

${ }^{21}$ Y. Leterrier, L. Boogh, J. Andersons, and J.-A. E. Månson, J. J. Polym. Sci., Part B: Polym. Phys. 35, 1449 (1997).

${ }^{22}$ P. C. P. Bouten, Y. Leterrier, and P. J. Slikkerveer, in Flexible Flat Panel Displays, edited by G. P. Crawford (Wiley, New York, 2005).

${ }^{23}$ M. Ignat, Key Eng. Mater. 116-117, 279 (1996).

${ }^{24}$ A. R. Hambley, Electrical Engineering: Principles and Applications, 3rd ed. (Pearson Education, Upper Saddle River, NJ, 2005).

${ }^{25}$ D. R. Cairns, R. P. W. Witte II, D. K. Sparacin, S. M. Sachsman, D. C. Paine, G. P. Crawford, and R. R. Newton, Appl. Phys. Lett. 76, 1425 (2000).

${ }^{26}$ M. R. Begley and H. Bart-Smith, Int. J. Solids Struct. 42, 5259 (2005).

${ }^{27}$ V. I. Vladimirov and R. G. Lupashki, Strength Mater. 5, 465 (1973).

${ }^{28}$ S. Giordano, Int. J. Appl. Electromagn. Mech. 26, 1 (2007).

${ }^{29}$ V. Palermo, A. Liscio, M. Palma, M. Surin, R. Lazzaroni, and P. Samori, Chem. Commun. (Cambridge) 2007, 3326. 